\title{
Effect of Sildenafil Citrate on Fetal Color Doppler Study and Biophysical Profile in Cases of Intrauterine Growth Restriction (IUGR) in Third Trimester Mohamed Hesham Hasan Anwar, Morad Kamel Hasanin, Bassem Ragab Abdelaziz, Omar Abd El Mageed Ismail Hamd * \\ Obstetrics \& Gynecology Department, Faculty of Medicine, Al-Azhar University \\ *Corresponding Author: Omar Abd El Mageed Ismail Hamd, E-mail: omardoda24@ yahoo.com
}

\begin{abstract}
Background: fetal growth restriction is an important cause of perinatal morbidity and mortality. The accurate assessment of fetal growth during pregnancy is difficult, but recent advances have improved this important aspect of obstetric care with positive implications for antenatal patients and their babies. Aim of the Work: to assess the effect of sildenafil citrate on color Doppler flow parameters in umbilical artery, Middle cerebral artery and Biophysical Profile in case of fetal growth restriction. Patients and Methods: this is a prospective cohort study of 100 pregnant females presenting for routine antenatal care at $28+0$ weeks till delivery. A cohort of 100 pregnant females attending the antenatal care clinics at Al-Hussein university hospital and Bab El-Sharia university hospital during a period of 2 years from May 2016 to May 2018. Results: this study excluded the patients with undetermined gestational age, intrauterine infection, high risk for aneuploidy (e.g. maternal age $>40$ years, detected congenital fetal anomalies in the current or previous pregnancies). All cases were followed regularly twice monthly during the seventh and eighth month and then once weekly till delivery, after the administration of $20 \mathrm{mg}$ of sildenafil citrate every 12 hourly starting from the 28 weeks of gestation until delivery. Conclusion: the current study conclude that, administration of Sildenafil $20 \mathrm{mg}$ every 12 hourly in pregnant females with fetal growth restriction (FGR) improved the feto-placental Doppler indices (pulsatility index and resistance index) of umbilical artery, middle cerebral artery.
\end{abstract}

Keywords: Sildenafil Citrate, Fetal Color Doppler, Intrauterine Growth Restriction, Biophysical Profile.

\section{INTRODUCTION}

Fetal Growth Restriction (FGR) represents a pathophysiological condition in which a foetus is restricted from reaching its genetically determined size. This distinguishes a FGR foetus from another who is simply small for gestational age (SGA) based on its genetic make-up (1). According to (the American College of Obstetricians and Gynecologists), FGR is "one of the Most common and complex problems in Modern obstetrics comprising about one-third of low birth weight babies. In developed countries, its overall incidence is about $2-8 \%$. The incidence among the term babies is about $5 \%$ and that among the post-term babies is about $15 \%{ }^{(2)}$. FGR foetuses have significantly elevated risks of intrauterine foetal demise, neonatal mortality, and short and long term complications ${ }^{(3)}$. The fetus is affected from the noxious effect very early in the phase of cellular hyperplasia most often caused by structural or Chromosomal abnormalities or congenital infection TORCH (Toxoplasma, others, rubella, cytomegalovirus, and herpes).The pathological process is intrinsic to the fetus and involves all the organs including Head. Current clinical management consists of close monitoring of foetal growth rates and well-being. Preterm delivery was indicated when foetal growth or well-being become so poor that the risks of intrauterine foetal demise are greater than the risks of prematurity ${ }^{(4)}$. Abdominal circumference (AC) measurement is the most sensitive parameter for detecting FGR ${ }^{(5)}$. EFW is determined from the average of three readings for each of the following: Femur length (FL), abdominal circumference (AC) and Biparietal diameter (BPD) ${ }^{(6)}$. Reduced flow and increased resistance in uterine and umbilical arteries, indicative of reduced uteroplacental flow in pregnancies with foetal growth restriction, have been documented by non-invasive Doppler ultrasound velocimetry ${ }^{(7)}$. A salient feature observed in FGR is the reduction of amniotic fluid volume. Amniotic fluid volume is estimated by a simple subjective assessment or calculation of the amniotic fluid index (AFI) ${ }^{(8)}$. Sildenafil citrate is a potent and selective inhibitor of cyclic guanosine monophosphate (cGMP) specific phosphodiesterase type 5 (PDE5) ${ }^{(9)}$. Sildenafil citrate and uteroplacental perfusion in fetal growth restriction: In a normal pregnancy, the trophoblast produces nitric oxide (NO) which plays an important role in vasodilatation in the fetoplacental circulation to improve oxygen and nutritional supply to the fetus ${ }^{(10)}$. Furthermore, Sildenafil citrate can improve fetoplacental perfusion in pregnancies complicated by intrauterine growth restriction. It could be a potential therapeutic strategy to improve uteroplacental blood flow in pregnancies with FGR ${ }^{(11)}$. 


\section{AIM OF THE WORK}

The aims of this study were: Firstly: to assess the effect of sildenafil citrate on color Doppler flow parameters in both umbilical artery (UA), Middle cerebral artery (MCA) and Biophysical Profile (BPP) in case of fetal growth restriction (FGR) proved by changes At gestational age 28+0 weeks till delivery. Secondly: Does sildenafil therapy improve fetal outcome in pregnant women with fetal growth restriction?

\section{PATIENTS AND METHODS}

Study design: This was a prospective cohort study on 100 pregnant females presenting for routine antenatal care at $28+0$ weeks till delivery. Study place: A cohort of 100 pregnant females attending the antenatal care clinics at Al-Hussein university hospital and Bab El-Sharia university hospital during the period of 2 years from May 2016 to May 2018. Ethical considerations: The study was approved and accepted by the Ethical and medical Research Committee of the Council of Obstetrics and Gynecology Department, Al-Azhar University. Full informed verbal explanation of the study aims and procedure was offered to all patients participated in the study and verbal consent (agreement) attained. Full informed written consent was signed by all patients participated in the study. Subjects: The candidates were selected according to the following inclusion and exclusion criteria. Inclusion criteria: These include the following: gestational age of $28+0$ weeks or more determined by the first day of last normal menstrual period (L.M.P.) or early first trimester ultrasound, singleton pregnancies with no fetal anomalies, Diagnosis as small for gestational age (SGA) by EFW < 10th percentile for gestational age. Exclusion criteria: multifetal pregnancies, cases with fetal anomalies, women with chronic hypertension or sever preeclampsia, women with known medical conditions e.g: diabetes mellitus, connective tissue diseases as SLE, anti-phospholipid antibody syndrome, thrombophilia's, sickle cell disease, chronic renal insufficiency, Preterm rupture of membrane (PROM), patient with contraindication of sildenafil citrate intake e.g: cardiovascular risk factors, severe hepatic impairment (decreased liver function), severe impairment in renal function, recent stroke or heart attack, hereditary degenerative retinal disorders. Ultrasound examinations: The instrument used in this study was Siemens Sonoline Sienna ultrasound machine with Doppler unit with trans-abdominal curvilinear probe at a frequency of 2.5-6 MHz. Statistical analysis: Recorded data were analyzed using the statistical package for social sciences, version 20.0 (SPSS Inc., Chicago, Illinois, USA). Quantitative data were expressed as mean \pm standard deviation (SD). Qualitative data were expressed as frequency and percentage.

\section{RESULTS}

Table (1): Maternal characteristics descriptive of the study group.

\begin{tabular}{|l|c|c|}
\hline \multicolumn{1}{|c|}{ Maternal characteristics } & Range & Mean \pm SD \\
\hline Age (years) & $24-35$ & $28.10 \pm 4.49$ \\
\hline Weight $(\mathrm{kg})$ & $61-91$ & $72.12 \pm 9.40$ \\
\hline BMI $\left(\mathrm{kg} / \mathrm{m}^{2}\right)$ & $22-34$ & $28.04 \pm 3.85$ \\
\hline & Range & Median $(\mathbf{I Q R})$ \\
\hline Parity & $0-4$ & $1(2)$ \\
\hline Number of previous miscarriages & $0-4$ & $0(1)$ \\
\hline
\end{tabular}

This table shows that the mean age was $28.10 \pm 4.49$ years, mean weight was $72.12 \pm 9.40 \mathrm{~kg}$, mean BMI was $28.04 \pm 3.85$, median parity 1 (2) and number of previous miscarriages 0 (1).

Table (2): The extent of the UA-RI difference over the treatment periods with sildenafil.

\begin{tabular}{|l|c|c|c|c|}
\hline \multicolumn{1}{|c|}{ UA-RI } & Mean \pm SD & Mean Diff. & t-test & p-value \\
\hline Before sildenafil & $0.85 \pm 0.06$ & & & \\
\hline After 2 weeks & $0.81 \pm 0.06$ & -0.04 & 1.640 & 0.566 \\
\hline After 4 weeks & $0.72 \pm 0.18$ & -0.13 & 2.317 & $0.047^{*}$ \\
\hline After 6 weeks & $0.63 \pm 0.22$ & -0.23 & 2.481 & $0.038^{*}$ \\
\hline After 8 weeks & $0.49 \pm 0.14$ & -0.36 & 3.052 & $0.022^{*}$ \\
\hline After 10 weeks & $0.42 \pm 0.15$ & -0.43 & 3.754 & $0.016^{*}$ \\
\hline
\end{tabular}

t- Paired Sample t-test

*p-value $<0.05$ significant; $\mathrm{p}$-value $>0.05 \mathrm{NS}$

This table shows statistically significant difference between (before and after) 4, 6, 8, 10 weeks of treatment according to UA-RI.

Table (3): The extent of the difference in the biophysical profile score over the treatment periods with sildenafil.

\begin{tabular}{|l|c|c|c|c|c|c|}
\hline \multirow{2}{*}{$\begin{array}{c}\text { Biophysical } \\
\text { Profile }\end{array}$} & \multicolumn{2}{|c|}{$6 / 8$} & \multicolumn{2}{c|}{$8 / 8$} & \multicolumn{2}{c|}{$\begin{array}{c}\text { Chi-square } \\
\text { test }\end{array}$} \\
\cline { 2 - 7 } & $\begin{array}{c}\text { No } \\
.\end{array}$ & $\%$ & $\begin{array}{c}\text { No } \\
.\end{array}$ & $\%$ & $\mathbf{x 2}$ & p-value \\
\hline Before sildenafil & 94 & $\begin{array}{c}100.0 \\
\%\end{array}$ & 0 & $0.0 \%$ & & \\
\hline After 2 weeks & 80 & $85.1 \%$ & 14 & $\begin{array}{c}14.9 \\
\%\end{array}$ & 1.767 & 0.588 \\
\hline After 4 weeks & 66 & $70.2 \%$ & 28 & $\begin{array}{c}29.8 \\
\%\end{array}$ & 5.743 & $0.037 *$ \\
\hline
\end{tabular}




\begin{tabular}{|l|l|l|c|c|c|c|}
\hline After 6 weeks & 47 & $50.0 \%$ & 47 & $\begin{array}{c}50.0 \\
\%\end{array}$ & 7.064 & $0.016^{*}$ \\
\hline After 8 weeks & 38 & $40.4 \%$ & 56 & $\begin{array}{c}59.6 \\
\%\end{array}$ & 8.689 & $\begin{array}{c}<0.001 * \\
*\end{array}$ \\
\hline After 10 weeks & 9 & $9.6 \%$ & 85 & $\begin{array}{c}90.4 \\
\%\end{array}$ & $\begin{array}{c}10.68 \\
8\end{array}$ & $\begin{array}{c}<0.001 * \\
*\end{array}$ \\
\hline
\end{tabular}

**p-value $<0.001 \mathrm{HS}$; *p-value $<0.05$ significant; p-value $>0.05 \mathrm{NS}$

This table shows statistically significant difference between (before and after) 4, 6, 8, 10 weeks of treatment according to biophysical profile.

Table (4): Relation between gestational age (wks.) and neonatal complications.

\begin{tabular}{|l|c|c|c|c|}
\hline \multirow{2}{*}{$\begin{array}{c}\text { Gestational } \\
\text { age (wks.) }\end{array}$} & \multicolumn{2}{|c|}{$\begin{array}{c}\text { Neonatal } \\
\text { complications }\end{array}$} & \multicolumn{2}{c|}{$\begin{array}{c}\text { Chi-square } \\
\text { term }\end{array}$} \\
\cline { 2 - 3 } & Yes & No & $\mathbf{x}^{2}$ & p-value \\
\hline $\begin{array}{l}\text { Term } \geq \mathbf{3 7} \text { wks. } \\
(\mathbf{N = 8 2})\end{array}$ & $6(7.3 \%)$ & $\begin{array}{c}76 \\
(92.7 \%)\end{array}$ & & \\
\hline $\begin{array}{l}\text { Preterm <37 } \\
\text { wks. } \\
(\mathbf{N = 1 2})\end{array}$ & $7(58.3 \%)$ & $5(41.7 \%)$ & $\begin{array}{c}18.78 \\
1\end{array}$ & $\begin{array}{c}<\mathbf{0 . 0 0 1 *} \\
*\end{array}$ \\
\cline { 1 - 3 } Total (N=94) & 13 & $\begin{array}{c}81 \\
(86.2 \%)\end{array}$ & & \\
\hline
\end{tabular}

This table reveals highly statistically significant relation between gestational age (wks.) and neonatal complications.

\section{DISCUSSION}

Foetal growth disorders are an important cause of perinatal morbidity and mortality. The accurate assessment of foetal growth during pregnancy is difficult, but recent advances have improved this important aspect of obstetric care with positive implications for antenatal patients and their babies ${ }^{(\mathbf{1 2})}$. SGA definition is based on the crosssectional evaluation (either prenatal or postnatal), and this term has been used for those neonates whose birth weight is less than the 10th percentile for that particular gestational age or two standard deviations below the population norms on the growth charts, and the definition considers only the birth weight without any consideration of the inutero growth and physical characteristics at birth ${ }^{(\mathbf{1 3})}$. Foetal Growth Restriction (FGR) represents a pathophysiological condition in which a foetus is restricted from reaching its genetically determined size. This distinguishes a FGR foetus from another who is simply small for gestational age (SGA) based on its genetic make-up ${ }^{(1)}$. Sildenafil citrate is a phosphodiesterase-5 (PDE-5) inhibitor. It acts by preventing the degradation of the second messenger cyclic guanosine $3^{\prime}, 5^{\prime}$-monophosphate by the enzyme PDE-5. This results in increased nitric oxide production and consequent vascular smooth muscle relaxation and an increase in vasodilation ${ }^{(\mathbf{1 4})}$. It was intended to administer Sildenafil in pregnancies with foetal growth restriction in an attempt to induce vasodilatation and improve utero-placental perfusion resulting in improved Doppler indices ${ }^{(15)}$. This study excluded the patients with undetermined gestational age, intrauterine infection, high risk for aneuploidy (e.g. maternal age $>40$ years, detected congenital foetal anomalies in the current or previous pregnancies) as well as Maternal cardiac disease, use of any vasodilator agents and known allergy to sildenafil. All cases were followed regularly twice monthly during the seventh and eighth month and then once weekly till delivery, after the administration of $20 \mathrm{mg}$ of sildenafil citrate every 12 hourly starting from 28 weeks of gestation (the gestational age at the time of diagnosis and Doppler examination) until delivery. The current study showed non statistical significant difference regarding maternal characteristics as age, weight, body mass index (BMI), parity and number of previous miscarriages. The current study found that, there was significant difference regarding umbilical and middle cerebral artery indices after sildenafil administration. The current studies showed that, there was a significantly higher mean birth weight in neonates and higher mean gestation at delivery in women with foetal growth restriction and have been treated with sildenafil citrate and this indicates the good prognosis and improvement of Doppler indices. The current study found that, there was a significant decrease regarding the preterm $<37$ wks and a significant increase regarding term $\geq 37$ wks of gestational age at time of delivery. Also, there was a significant increase regarding normal Birth weight (gm) of gestational age at time of delivery. There was a highly statistically significant relation between the increases of gestational age at time of delivery (term $\geq 37$ wks.) and decreased neonatal complications. There was a statistically significant difference in headache and palpitations / sweating in patient's received sildenafil. Another case report matching with this current study results was conducted by Choudhary et al. (16) showed an improvement in Doppler indices and an increase in 
fetal weight after starting sildenafil citrate $25 \mathrm{mg}$ vaginally twice a day in a pregnant with abnormal umbilical artery Doppler. Also Von Dadelszen et al. ${ }^{(17)}$ carried out a case control study done on pregnant women with FGR, found that a significant increase in abdominal circumference in neonates of patient received sildenafil citrate $25 \mathrm{mg}$, three times daily until delivery. There were no adverse maternal sideeffects of Sildenafil in this study. In addition, Samangaya et al. ${ }^{(18)}$ found that there was a similar incidence within each group as regards neonatal complications and side effects of Sildenafil.

\section{CONCLUSION}

The current study concluded that, administration of Sildenafil $20 \mathrm{mg}$ every 12 hourly with pregnancies with fetal growth restriction (FGR) improved the feto-placental Doppler indices (pulsatility index and resistance index) of umbilical artery, middle cerebral artery, biophysical profile and improved neonatal outcomes. This was most probably as Sildenafil improves the placental perfusion. Furthermore, Sildenafil treatment may offer a new opportunity to decrease perinatal morbidity and mortality rates.

\section{CONFLICTS OF INTEREST}

There are no conflicts of interest.

\section{REFERENCES}

1. Platz E and Newman R (2008): Diagnosis of IUGR: traditional biometry. Semi Perinatal., 32:140-147.

2. American College of Obstetricians and Gynecologists (2009): Intrauterine growth restriction. https://www.ncbi. nlm.nih.gov/pubmed/19217594

3. Rosenberg A (2008): The IUGR newborn. Semi Perinatal, 32:219-224.

4. Turan S, Miller J and Baschat AA (2008): Integrated testing and management in fetal growth restriction. Semi Perinata., 32:194-200.

5. Snijders RJ and Nicolaides KH (1994): Fetal biometry at 14-40 weeks' gestation. Ultrasound Obstet Gynecol., 4:34-48.
6. Benson CB, Doubilet PM and Saltzman DH (1985): FL/AC ratio: poor predictor of intrauterine growth retardation. Invest Radiol., 20:727.

7. Dastjerdi MV, Hosseini S and Bayani L (2012): Sildenafil citrate and uteroplacental perfusion in fetal growth restriction. J Res Med Sci., 17: 632-636.

8. Moore TR and Cayle JE (1990): The amniotic fluid index in normal human pregnancy, American Journal of Obstetrics and Gynecology, 162(5): 1168-1173.

9. Ballard SA, Gingell CJ and Tang K (1998): Effects of sildenafil on the relaxation of human corpus cavernosum tissue in vitro and on the activities of cyclic nucleotide phosphodiesterase isozymes AMJ Urol., 159(6):2164-71.

10. Rosselli M, Keller RJ and Dubey RK (1998): Role of nitric oxide in the biology, physiology and pathophysiology of reproduction. Hum Reprod Update, 4:3-24.

11. Dastjerdi MV, Hosseini $S$ and Bayani $L$ (2012): Sildenafil citrate and uteroplacental perfusion in fetal growth restriction. J Res Med Sci., 17: 632-636.

12. Cunningham GC, Williams RL and Creasy RK (1982): Fetal growth and perinatal viability in California. Obstet Gynecol., 59:624.

13. Sharma D, Sweta $S$ and Pradeep $S$ (2016): Intrauterine Growth Restriction: Antenatal and Postnatal Aspects. Clinical Medicine Insights: Pediatrics, 10 67-83.

14. Mehrotra N, Gupta $M$ and Kovar A (2007): The role of pharmacokinetics and pharmacodynamics in phosphodiesterase5 inhibitor therapy. Int J Impot Res., 19: 253-264.

15. Wareing M, Myers JE and O'Hara M (2005): Sildenafil citrate (Viagra) enhances vasodilatation in fetal growth restriction. J Clin Endocrinal Metab., 90: 2550-2555 
16. Choudhary R, Kavita $D$ and Hetal $P$ (2016): Sildenafil citrate for the management of fetal growth restriction and oligohydramnios Int $\mathrm{J}$ Women's Health, 8: 367-372.

17. Von Dadelszen P, Ornstein MP and Bull SB (2000): Fall in mean arterial pressure and fetal growth restriction in pregnancy hypertension: a meta-analysis. Lancet, 355:87.

18. Samangaya RA, Mires G and Shennan A (2009): A randomised, double-blinded, placebo-controlled study of the phosphodiesterase type 5 inhibitor sildenafil for the treatment of preeclampsia. Hypertens Pregnancy, 28(4):369-382. 